\title{
KONSEP MANUSIA DAN KOMUNIKASI DALAM PERSPEKTIF PSIKOLOGI TRANSPERSONAL DAN ISLAM
}

\author{
Pasiska \\ Mahasiswa PPs UIN Sunan Kalijaga Yogyakarta \\ bruspasiska@gmail.com
}

\begin{abstract}
This paper analyzes more deeply on how transpersonal psychology is one of the fields in psychology that integrates psychological concepts, theories, and methods with spiritual wealth from various cultures and religions. The core concept of transpersonal psychology is nonduality, the knowledge that each part of human is part of the whole universe. Cosmic union that sees everything as a whole. Transpersonal psychology focuses more on spiritual or transcendental aspects of humans. Further, the transpersonal in the Islamic concept is more optimizing human potential for values to Godhead, which is done by Sufi as an effort to find out a way to God, starting from tobat, zuhud, ridha, tawadhu, mahabbah and ma'rifah as the manifestations of an optimization of Godhead values in human beings. The transpersonal psychology aspect is highly correlated with Islam particularly in the field of mental illness healing which is done through salat, fasting, dzikir (remembering God), doa (praying), and hajj (pilgrimage).
\end{abstract}

Keywords: human, psychology, transpersonal

\begin{abstract}
Abstrak
Artikel ini mengungkap lebih dalam bagaimana psikologi transpersonal sebagai salah satu bidang psikologi yang mengintegrasikan konsep, teori, dan metode psikologi dengan kekayaan spritual dari bermacam-macam budaya dan agama. Konsep inti dari psikologi transpersonal adalah non-dualitas (nonduality), suatu pengetahuan bahwa tiap-tiap bagian (manusia) adalah bagian dari keseluruhan alam semesta. Penyatuan kosmis yang memandang segala-galanya sebagai satu kesatuan. Psikologi transpersonal lebih menitikberatkan pada aspek-aspek spiritual atau transendental dalam diri manusia. Kemudian transpersonal dalam konsep Islam lebih optimalisasi potensi manusia terhadap nilai-nilai Ketuhanannya, yang dilakukan dikalangan sufi dalam upaya menemukan jalan menuju kepada Tuhan, dimulai dari tobat, zuhud, ridha, tawadhu, mahabbah dan ma'rifah yang mana manifestasi dari hal tersebut ialah optimalisasi nilai-nilai Ketuhanan dalam diri manusia. Aspek psikologi transpersonal yang sangat berkeorelasi dalam Islam khususnya dalam bidang penyembuhan penyakit mental ialah melalui sholat, puasa, dzikir, doa,dan haji.
\end{abstract}

Kata Kunci: manusia, psikologi, transpersonal 


\section{Pendahuluan}

Perkembangan keilmuan di bidang psikologi berjalan begitu pesat. Hingga saat ini, dimana dalam berbagai macam bidang disiplin keilmuan yang mana fungsi praktisnya diperuntukkan untuk manusia, dengan kosepsi manusia dengan berbagai persepektif untuk mengkaji tentang makana atau pengertian tentang manusia itu sendiri.

Seperti Socrates mendefenisikan bahwa manusia itu hewan bermasyarakat, Max Schaller menyebutkan bahawa manusia itu mahluk yang gelisah dan menyakitkan dalam bukunya (Drijarkara, 1978:138). Kemudian ada beberapa defenisi lain tentang manusia diantaranya Homo Sapiens atau manusia berakal budi, Homo Faber, hewan yang pandai membuat, Homo economicus, mahluk ekonomi, Homo religious atau mahluk beragama (Zuhairini, 2009:82). Pulo Freire, bahwa manusia itu merupakan mahluk yang memilki potensi dengan mengembangkan diri melalui pendidikan, dalam (Abidin, 2018:3). Defenisi lain mengenai manusia menurut Ali Rahmat, Ibn Sina, bahwa hakikat manusia itu terdiri dari jasad dan Nafs yang selalu memerlukan bimbingan agar menjadi pembeda antara manusia dan hewan, sedangkan Al-Ghazali menyatakan bahwa hakikat manusia itu memiliki potensi Nafs, ruh, hati dan akal, yang apanila potensi ini terus dibimbing kejalan baik akan menjadi manusia yang beradab (Rahmat, 2017:37).

Mazhab Psikologi yang berupaya mendefenisiskan tentang manusia ialah konsep manusia dalam persepektif Psikologi Eksistensial menurut Ludwig Binswanger, Dunia manusia memiliki eksistensi meliputi tiga wilayah (Hambali \& Jaenudin, 2013:101), yaitu: (1) Umweit (lingkungan), adalah dunia objek dan benda di sekitar kita. Termasuk di dalamnya adalah dorongan biologis, rasa lapar, mengantuk, bahkan kelahiran dan kematian. (2) Mitweit (dunia bersama), adalah dunia penghubung antar manusia. Dalam perhubungan tersebut terdapat perasaan cinta ataupun benci yang tidak dapat dipahami hanya sebagai sesuatu yang bersifat 
biologis. Pada dunia ini individu diminta untuk dapat menghormati desain orang lain. (3) Eigenweit (dunia milik sendiri), adalah kesadaran diri akan hubunganseseorang dengan dirinya sendiri. Pada Eigenweit manusia dituntut untuk sadar akan dirinya sebagai manusia.

Boss menggunakan istilah dasein analysis yang kemudian dimaknai sebagai penjelasan cermat tentang hakikat khas eksistensi manusia. Analisis Dasein berusaha melihat sesuatu yang ada pada pengalaman seseorang secara subjektif dan menjelaskannya setepat mungkin sebatas kemampuan bahasa. Boss menyatakan bahwa semua gejala patologis (baik fisik maupun psikologis) yang tampak harus dianggap sebagai perusakan atas pemenuhan eksistensi manusia yang bebas dan terbuka. Konsep ini bertentangan dengan pandangan ilmiah orang-orang barat yang menggunakan konsep kausalitas (Hall \& Lindzey, 1995:186). Setiap individu memiliki kebebasan untuk memilih, dan ia bertanggungjawab terhadap eksistensinya sendiri.

Kemudian mazhab Psikologi Posivistik juga mendefenisikan konsep manusia, menurut Seligman ada tiga cara yang tepat untuk memperoleh suatu kebahagiaan (Seligman, 2005:56), yaitu: (1) Miliki kehidupan yang menyenangkan. Melalui hidup yang menyenangkan, manusia akan memperoleh kebahagiaannya. Kehidupan semacam ini dekat dengan kehidupan hedonis dan cenderung berujung pada terkena drabness atau jebakan kebosanan. (2) Miliki kehidupan yang baik. Konsep ini pertama kali dibawa oleh Aristoteles, yang ia sebut dengan eudaimonia atau keterlibatan pribadi dalam pekerjaan, hubungan atau kegiatan sehingga hanyut dalam "flow" sehingga merasakan seakan waktu berhenti karena kita sangat menghayati dan khusyu. (3) Miliki kehidupan bermakna. Melalui semangat melayani, berkontribusi dan berorientasi untuk memberikan kebaikan dan manfaat kepada orang lain maka kebahagiaan bisa diraih. Psikologi positif menekankan nilai-nilai positif yang dimiliki manusia, salah satunya melalui tema kebahagiaan 
(Seligman, 2005). Selain itu dia juga berpendapat bahwa salah satu cara memperoleh kebahagiaan adalah dengan cara memberikan kebaikan kepada orang lain.

Dari beberapa defenisi para tokoh ahli dan penelitian menganai hakikat manusia dengan pendekatan-pendekatannya maka penulis akan mendefenisikan hakikat manusia dengan defenisi 'psikologi transpersonal'.Psikologi sebagai disiplin ilmu telah melahirkan banyak pandangan dan teori-teori psikologi. Bahkan satu sama lain bisa saling berbeda atau bahkan saling bertentangan dalam pandangan serta ciriciri khas yang dimilikinya. Beberapa diantaranya adalah cabang teori Psikologi Eksistensial, Psikologi Positif, dan Psikologi Transpersonal.

Ada beragam pandangan dan teori-teori psikologi yang telah dikemukakan oleh banyak tokoh psikologi, membuat kita perlu untuk memahami dan mampu membedakan antara satu dengan yang lainnya. Tidak hanya pemaparan teori saja yang perlu dipahami, tapi juga harus dimulai dari sejarah perkembangannya, tokoh-tokoh pendukungnya, bahkan keterkaitan dengan konsep Islam.

\section{Psikologi Transpersonal}

Secara etimologis, transpersonal berarti melampaui gambaran manusia yangkelihatan. Dengankatalain, transpersonalberartimelampaui macam-macam topeng yang digunakan manusia. Menurut John Davis, psikologi transpersonal bisa diartikan sebagai ilmu yang menghubungkan psikologi dengan spritualitas. Psikologi transpersonal merupakan salah satu bidang psikologi yang mengintegrasikan konsep, teori, dan metode psikologi dengan kekayaan spritual dari bermacam-macam budaya dan agama. Konsep inti dari psikologi transpersonal adalah nondualitas (nonduality), suatu pengetahuan bahwa tiap-tiap bagian (manusia) adalah bagian dari keseluruhan alam semesta. Penyatuan kosmis yang memandang segala-galanya sebagai satu kesatuan (Jaenudin, 2012:25). 
Perintisan psikologi transpersonal diawali dengan penelitian tentang psikologi kesehatan pada tahun 1960-an yang dilakukan oleh Abraham Maslow. Perkembangan psikologi transpersonal lebih pesat setelah terbitnya journal of transpersonal psychology pada tahun 1969 pada masa disiplin ilmu psikologi mulai mengarahkan perhatian pada dimensi spiritual manusia. Penelitian mengenai gejala-gejala rohaniah, pengalaman transpersonal, aktualisasi, dan pengalaman transpersonal mulai dikembangkan (Jaenudin, 2012:26).

Aliran psikologi transpesoanal memproklamasikan diri sebagai aliran keempat setelah psikoloanalisis, behaviorisme, dan humanistik. Akan tetapi dapat dikatakan bahwa aliran ini merupakan perkembangan dari aliran humanistik. Sebuah definisi yang dikemukakan oleh Shapiro yang merupakan gabungan dari pendapat tentang psikologi transpersonal, bahwa psikologi transpersonal mengkaji potensi tertinggi yang dimiliki manusia, dan melakukan penggalian, pemahaman, perwujudan dari kesatuan, spiritualitas, serta kesadaran transedensi.

Psikologi transpersonal lebih menitik beratkan pada aspekaspek spiritual atau transendental dalam diri manusia. Hal inilah yang membedakan konsep manusia antara psikologi humanistik dan psikologi transpersonal. Mc Waters (dalam Nusjirwan, 2001:40) membuat sebuah diagram yang berbentuk lingkaran bahwa setiap lingkaran mewakili satu tingkat berfungsinya manusia dan tingkat kesadaran diri manusia.

Secara garis besar, seperti yang dikemukakan oleh Lajoie dan Shapiro dalam journal of transpersonal psychology, psikologi transpersonal didefinisikan sebagai studi mengenai potensi tertinggi dari manusia melalui pengenalan, pemahaman, dan realisasi terhadaap keesaan, spritualitas dan keterikatan berbagai bentuk agama yang ada. Sekalipun demikian, dalam penelitiannya, psikologi transpersonal mengkaji pengalaman spiritual yang dialami oleh para ahli spritual yang berasal dari berbagai macam agama sebagai subjek penelitiannya. 
Dalam kajian psikologi transpersonal disebutkan bahwa potensi tertinggi dari individu terdapat pada dunia spiritual yang bersifat nonfisik. Hal ini ditunjukkan dengan berbagai pengalaman, seperti kemampuan melihat masa depan, extrasensory perception (ESP), pengalaman mistik, perkembangan spritualitas, pengalaman puncak, meditasi, dan berbagai macam kajian yang bersifat parapsikologi atau metafisik. Dengan menyadari keadaan manusia yang bukan hanya terletak pada dunia fisik dan meyakini bahwa inti terpenting dari individu terletak pada dunia spiritual yang bersifat kasat mata dan abstrak dengan kata lain, psikologi transpersonal memandang kita sebagai makhluk spiritual yang memiliki pengalaman manusia dan bukanlah manusia yang memiliki pengalaman spritual.

Dengan demikian perhatian psikologi transpersonal erat kaitannya dengan perhatian yang diberikan oleh tradisi-tradisi mistik. Meskipun secara pragmatik, posisi psikologi transpersonal di posisikan yang secara radikal berbeda dengan posisi sebgaian besar aliran utama psikologi barat, yang cenderung menganggap agama atau spiritualitas didasarkan atas takhayul primitive, penyimpangan patologis yang sama-sama ditanamkan oleh system keluarga dan kebudayaan. Meskipun pendekatan system dalam psikologi ini mempunyai persepektif holistik dan dinamis, konsep holistiknya yang kecenderungan mengarah pada konsep Gestalt, yang mengemukakan bahwa sifat dan fungsi psyche tidak difahami dengan mereduksinya menjadi unsur-unsur yang terpisah. Sementara persepektif dinamis dalm psikologi ini merupakan pengembangan dari pandangan Jung yang telah sampai pada pemikiran dinamika mental dalam alur energy, maka para psikolog transpersonal mempercayai bahwa dinamikadinamika tersebut mencerminkan suatu intelegnsi intrinsi, yang memungkinkan psyche tidak hanya menghasilkan penyakit mental tetapi juga menyembuhkan dirinya sendiri (Capra, 1997:527), dengan demikian pertumbuhan batin dan aktualisasi diri dipandang sebagai hal-hal yang esensial bagi dinamika psyche manusia yang sepenuhnya cocok dengan transendensi diri dalam system pandangan hidup. 


\section{Tokoh Penting Psikologi Tranpersonal}

Tokoh psikologi transpersonal adalah William James, ia lebih dikenal sebagai penggagas pragmatisme dalam filsafat. Seperti halnya behaviorisme dalam psikologi yang lebih cocok dengan semangat amerika, pragmatisme pun mewakili pandangan metafisika amerika, William James dengan pragmatismenya memberikan sumbangan orisinal bagi dunia filsafat. Istilah pragmatisme berasal dari bahasa Yunani, pragma yang berarti tindakan maka pragmatisme diartikan sebagai filsafat tentang tindakan. Ini berarti bahwa pragmatisme bukan merupakan sistem filosofis siap pakai yang sekaligus memberikan jawaban terakhir seputar problem filosofis. Pragmatisme hanya berusaha menentukan konsekuensi praktis dari masalah-masalah itu, dan bukan memberikan jawaban finalnya. Salah satu karya William James yang penting dalam bidang psikologi agama, merupakan karya pertama yang membahas pengalaman religius adalah the varieties of religious experience.

Pembahasan pertama mengenai perbedaan antara sistem penyimpanan jangka pendek dan jangka panjang dicetuskan pertama kali oleh seorang psikolog Amerika William James di akhir abad sembilan belas, James menyebut dua bentuk memori ini sebagai primary memory (memori primer) dan secondary memory (memori sekunder). Ia menggunakan istilah ini untuk menunjukkan tingkatan hubungan antara informasi yang disimpan dengan kesadaran James (dalam Jenudin, 2012: 86). Dalam pandangan James, memori primer merupakan tempat penyimpanan awal di mana informasi dapat disimpan dan tersedia ketika mansuia memusatkan kesadaran, perhatian dan introspeksi. Dengan cara ini, informasi tersebut akan senantiasa dapat diakses. James berkata, sebuah objek memori primer tidak akan pernah hilang. Ia membedakan memori primer dengan sistem penyimpanan jangka panjang atau memori sekunder dalam hal informasi yang tidak bisa dimunculkan tanpa mengawalinya dengan sebuah proses kognitif aktif. Kaitan antara memori kerja dan 
kesadaran yang diteliti James merupakan bagian yang sangat penting dari pemikiran yang tumbuh pada saat ini. Pertanyaan mengenai apakah kita menyadari atau tidak keseluruhan konten dalam memori kerja masih menjadi perdebatan. Beberapa model terkini menunjukkan bahwa hanya sub-rangkaian memori kerjalah yang disadari (Jaenudin, 2012: 40).

Carl Jung diakui sebagai salah seorang di antara ahli-ahli pikir psikologi yang terkemuka abad XX. Selama 60 tahun, ia mengabdikan dirinya dengan segenap tenaga dan tujuan tunggal untuk menganalisis proses-proses kepribadian manusia yang sangat luas dan dalam. Tulisantulisannya sangat banyak dan pengaruhnya tidak dapat diukur. Ia terkenal tidak hanya di kalangan para psikolog dan para psikiater tetapi juga di kalangan orang-orang terdidik di semua bidang kehidupan (Jaenudin, 2012: 91) Banyak tanda jasa dianugerahkan kepadanya, antara lain gelargelar kehormatan dari Universitas Harvard dan Oxford. Ia sering memberi kuliah di Amerika serikat dan di negara ini ia memiliki banyak pengikut dan pengagum, sebenarnya seluruh tulisan jung sekarang tersedia dalam 20 jilid, terbitan dalam bahasa Inggris, terbitan dalam bahasa Inggris (Jung, 1973, 1975), ada juga satu jilid buku berisi wawancara-wawancara dan percakapan-percakapan dengan Jung (McGuire, 1977:5).

Tokoh ketiga Maurice Bucke (1837-1902) salah satu tokoh yang kurang dikenal dalam bidang psikologi. Ia mencoba menawarkan gagasan teori psikologi pertama yang menempatkan model kesadaran manusia dan realitas sebagai elemen transpersonal yang terbuka dan melestarikan dogma agama meskipun penelitiannya didasarkan pada pengalaman hidupnya, pada tahun 1872, saat ia mengalami peristiwa yang mengubah hidupnya ketika ia memiliki pengalaman mistik yang dipandang sebagai kesadaran kosmik, setelah pengalaman yang mendalam tentang kedekatan (sebuah pengalaman yang intens hubungan dengan alam semesta), ia menghabiskan seperempat abad berikutnya meneliti dan menulis sebuah buku yang berjudul Cosmic Consciousness (1902). Meskipun menyelesaikan 
proyek ini pada tahun 1898, ia tidak menemukan penerbit sampai sebelum kematiannya pada 1901, dan lebih dari 100 tahun kemudian dicetak (1992) (Shorrock, 2008: 146).

Tokoh keempat ialah Alberto Assagioli merupakan tokoh yang pertama kali menggunakan istilah transpersonal dalam psikoterapi, dala era yang sama ketika Jung mengembangkan teori-teorinya, Roberto, seorang psikiater muda Italia ini juga tertarik pada aspek niskala dari sifat manusia, ia juga merumuskan teori-teori yang berbicara tentang psikologi secara eksplisit termasuk transpersonal yang dikenal dengan konsep psikosintesis. Di mana orientasinya menangani orang secara keseluruhan, baik fisik, mental, emosional dan spiritualnya (Whitmore, 1991: 142).

\section{Konsep Manusia Menurut Psikologi Transpersonal}

Psikologi merupakan ilmu pengetahuan yang mempelajari pengalaman-pengalaman yang timbul dalam diri manusia, seperti penggunaan pancaindera, pikiran, perasaan, dan kehendaknya. Ada empat konsep asas dalam psikologi, yaitu naluri, keperluan, desakan dan motivasi (Jaenudin, 2012): (1) Naluri adalah tenaga atau kuasa awal yang mendorong seorang individu untuk bertindak dengan cara tertentu. Ia merupakan tingkah laku yang diwarisi sejak lahir dan tidak diperoleh dari pengalaman ataupun pelajaran. (2) Keperluan adalah keinginan memenuhi kekurangan seorang individu dariaspek fisiologi dan psikologi. (3) Desakan adalah tindakan atau perubahan tingkah laku akibat satu-satu keperluan fisiologi yang tidak dipenuhi. Ia merupakan kecendrungan untuk mengekalkan keseimbangan suatu keadaan fisiologi seperti lapar dan dahaga. (4) Motivasi adalah perangsang yang membangkitkan dan mengekalkan minatseorang individu ke arah mencapai suatu sikap tertentu, termasuk mengubah sikap, minat dan tingkah lakunya. Hal ini diwujudkan karena adanya keperluan fisiologi atau psikologi. 


\section{Relevansi Psikologi Transpersonal dengan Islam}

Robert Frager, seorang mursyid sufi sekaligus profesor psikologi pada Institute of Transpersonal Psychology, California, mengulas komparasi tajam antara psikologi barat dan psikologi sufi, yang menjelaskan secara tegas bahwa tasawuf merupakan pendekatan holistik yang mengintegrasikan fisik, psikis dan spirit serta membimbing jiwa untuk tidak terjebak dalam bahaya model yang linear dan hierarkis, yang cenderung mengesampingkan dan membenarkan penindasan terhadap kaum perempuan dan minoritas. Tasawuf adalah disiplin pengetahuan (spiritual) yang dapat dimiliki oleh budaya, siapapun, kapanpun dan di mana pun (Jaenudin, 2012:162). Tetapi dilain sisi Tasawuf juga sebagai aspek mistisme dalam Islam, pada intinya adalah kesadaran adanya hubungan komunikasi manusia denan Tuhannya, yang selanjutnya adanya rasa bentuk rasa dekat (qurb) dengan Tuhannya (Jaenudin, 2012:162). Hunbungan tersebut dimaknai dengan pengalaman spiritual manusia dengan Tuhannya. Komunikasi itu mulai terjadi pada masa mansia berada di dalam rahim dalam kontak perjanjian primordial antara Tuhan dan manusia sebelum lahir, sebagaimana yang firman Allah surat al-A'raf ayat 172 yang artinya: Dan (ingatlah), ketika Tuhanmu mengeluarkan keturunan anak-anak Adam dari sulbi mereka dan Allah mengambil kesaksian terhadap jiwa mereka (seraya berfirman): "Bukankah Aku ini Tuhanmu?" Mereka menjawab: "Betul (Engkau Tuhan kami), kami menjadi saksi". (Kami lakukan yang demikian itu) agar di hari kiamat kamu tidak mengatakan: "Sesungguhnya kami (bani Adam) adalah orang-orang yang lengah terhadap ini (keesaan Tuhan)" Cordova 2007: 173).

Tujuan akhir dari ajaran tasawuf tidak lain mendekatkan diri kepada Allah dalam rangka mencari ridhanya, tentu saja melalui latihanlatihan yang bersifat spiritual agar dapat memperoleh jiwa yang suci serta dihiasi dengan ahlak yang baik. Prinsif hidup tasawuf sebenarnya sudah dilakukan oleh Rasulullah seperti hidup sederhana, tidak berlebihan, 
syukur, dan tawadhu. Upaya lain yang dilakukan juga ditempu oleh kalangan sufi yang melakukan pendekatan dengan Allah dengan melalui stasiun-stasiun tertentu seperti, zuhud, wara', tobat, raja', khauf, sabar dan seterusnya sampai pada puncaknya ketiga tingkat ma'rifat, dan bahkan sampai pada fana, bersatu dan menyatu dengan Tuhan. (Jaenudin, 2012:164).

Dan maqom yang harus dijalani yang umumnya dilakukan para sufi diantaranya sebagai berikut: (1) Maqam Tubat. Konsep taubat menurut Ibn Al-Qayyim Al-Jauziayyah (dalam Jaenudin, 2012: 166) adalah kembalinya seseorang hamba kepada Allah dengan meningglakan jalan orang-orang yang dimurkai Allah, tidak mengulangi lagi perbuatan tersebut serta berupaya sadar atas kesalahan dengan memperbaiki dengan perilaku-perilaku yang baik, seperti dalam surat al-Maidah ayat 39, yang artinya; Maka barangsiapa bertaubat (di antara pencuri-pencuri itu) sesudah melakukan kejahatan itu dan memperbaiki diri, maka sesungguhnya Allah menerima taubatnya. Sesungguhnya Allah Maha Pengampun lagi Maha Penyayang (Cordova, 2007:114). Hanya orang yang bertaubat kepada Allahlah yang akan diampuni meskipun seseorang pernah melakukan perbuatan dosa, keji, mungkar dan lain-lain, karena dengan tobat jiwa yang kotor akan dibersihkan serta dimaafkan atas kesalahan yang pernah dilakukan tentunya atas rahmat dan kasi sayang Allah SWT. (2) Maqam Zuhud. Dikarenakan tobat merupakan gerbang awal seorang sufi untuk menuju kelajalan Allah maka maqam yang harus dilalui oleh seornag sufi ialah maqam zuhud, yang secara terminology bermaknakan meninggalkan segala senuatu yang bersifat duniawi, untuk dekat dengan Allah harus dengan apa adanya dan melupakan segala kegemerlapan didunia yang justru akan membuat orang lupa akan Tuhannya (AlGhazali dalam Jaenudin, 2012: 170). Semakin kita memikirkan dunia ditakutkan akan melupakan Tuhan yang menciptakan manusia dan apabila manusia terlalu memikirkan dunia ia akan hanyut dalam kejaran yang tiada akhir. (3) Maqam Sabar. Seorang sufi dalam upaya melakukan 
mendekatkan diri kepada Allah juga harus melalui maqam sabar, sabar yang dimaksud bukanlah menahan diri dan berpasrah diri tepati sabar yang ingin dicapai ialah kemampuan seseorang dalam menahan diri dalam memikul penderitaan, menerima penerimaan tugas dalam bentuk suruhan dan larangan ataupun bentuk perlakuan serta sikap menghadapi musibah yang datang. Di jelaskan dalam al-Qur'an surat Hud ayat 39, yang artinya: Itu adalah di antara berita-berita penting tentang yang ghaib yang Kami wahyukan kepadamu (Muhammad); tidak pernah kamu mengetahuinya dan tidak (pula) kaummu sebelum ini. Maka bersabarlah; sesungguhnya kesudahan yang baik adalah bagi orang-orang yang bertakwa (Cordova 2007: 254). Maka konsep sabar yang dimaksud tidak lain untuk menjadikan manusia itu menjadiorang-orang yang menang dan selalu ingat kepada Allah sebagai Tuhan yang mendatangkan musibah dan mengkat juga musibah itu sebagaia pelajaran bagi manusia. Dan pada dasarnya tidak kekuatan yang berkuasa selain dari kekuasaan Allah semata yang maha kuasa atas segala sesuatu yang meliputi langit dan bumi. (4) Maqam Tawakal. Menyerahkan diri kepada Allah seutuhnya ketika telah berusaha sungguh-sungguh dalam upaya melakuakn segala bentuk perjuangan yang baik sesuai dengan yang diperintahkan Allah semata dan berusaha dengan sungguhsungguh menjauhkan diri atas apa yang dilarangnya, dan menyerahkan hasil dari apa yang dilakukan hanya kpada Allah, hal ini merupakan janaln yang harus ditempuh seorang sufi agar bisa menjadi ajang penempahan diri. (Imam Al-Qusyariry dalam Jaenudin, 2012: 174). (5) Maqam Rida. Selepas melewati maqam tawakal seorang sufi akan naik ke maqam rida di mana merupakan puncak dari kecintaan seorang sufi yang telah diperoleh selepas menjalani ubudiyyah yang panjang kepada Allah Swt. Karena rida merupakan anugerah yang diberikan atas usaha yang maksimal dalam pengabdian dan munajat, rida juga manifes dari amal saleh sehingga memperoleh pahaladari kebaikan yang telah dijalankan (Imam AlQusyariry dalam Jaenudin, 2012: 176). Artinya pahala yang peroleh tidak serta-merta didapt dengan mudah dengan kebaikan sekali atau kali 
tetapi harus ada usaha keras serta munajat dengan penuh dedikasi agar mendapatkan angugerah berupa pahala. (6) Maqam Mahabbah. Secara harfiah mahabbah merupakan pengertian cinta dan kasih sayang. Dalam hal ini mahabbah adalah usaha mewujudkan rasa cinta dan kasih sayang kepada Allah SWT. Mahabbah juga bisa diatrikan sebagai luapan dan gejolak hati keinginan bertemu dengan kekasih, yaitu Allah SWT Imam Al-Qusyariry dalam Jaenudin, 2012: 177). Cinta yang sesungguhnya membawa kepada keridaan ilahi, bagi orang yang merealisasikan cinta, ia akan mengorbankan apa saja dan dengan pengorbanan itu, dia sampai pada tujuan cintanya, cirinya ialaha menyukai kepatuhan kepada Allah dan membenci sikap melawannya, menyerahkan diri dan jiwanya kepada yang dikasih, mengosongkan hati dari segala-galanya kecuali dari yang dikasih, yaitu Allah semata. (7) Maqam Ma'rifat. Permaknaan ma'rifat, tasawuf sering dikonotasikan pada panggilan hati melalui bentuk tafakur untuk menghayati nilai-nilai akan kerinduan yang berhasil dari kegiatan berzikir, sesuai dengan tanda-tanda pengungkapan hakikat yang berterusan, maksudnya, hati yang menyaksikan kekuasaan Tuhan dan merasakan kebesarannya, kebenarannya dan mulia kehebatannya sehingga tidak dapay diungkapkan dengan kata-kata, kecuali terdiam menyaksikan dan merenungi. Pada level ini seorang sufi mengataka: diamana letak sanubari melihat yang dilihat hanya Allah, apabila melihat cermin yang dilihat hanya Allah, dan ketika bangun tidur yang dilihat hanya Allah, tetapi mata yang dimaksud ialah hati sanubari yang merasakan bahwa Allah itu sangat dekat dengannya (Harun Nasution dalam Jaenudin, 2012: 197).

Kemudian aspek lain yang dilihat didalam kajian sufistik diri atau nafs dalam psikologi sufi adalah aspek psikis pertama yang menjadi musuh kita. Akan tetapi, nafs bisa menjadi teman yang sangat berharga bagi kita dan tidak terhingga nilainya.Secara sederhana, nafs memiliki beberapa tingkatan.Tingkat terendah adalah nafs tirani.Ia merupakan nafs yang dapat menjauhkan kita dari spiritualitas. Pada sisi lain, tingkat 
tertinggi adalah nafs yang suci. Pada tingkat ini, kepribadian mencapai tingkat optimal bagaikan mencapai tingkat kesempurnaan yang dapat memantulkan cahaya ilahi (Jaenudin, 2012:161).

Jika manusia ingin mengaktualisasikan dirinya agar senantiasa dekat dengan Tuhan yang menciptakannya, maka ia harus menggunakan potensi yang positif untuk mengerjakan kebajikan dan menjauhkan dirinya dari hal-hal yang negatif. Intinya, yang dapat penulis simpulkan dalam pendekatan tasawuf ini adalah manusia harus selalu menghadirkan Tuhan didalam dirinya, agar perilakunya senantiasa dihiasi oleh amal kebajikan (Jaenudin, 2012: 161).

Terakhir, jiwa. Dalam psikologi sufi, jiwa diidentikkan dengan sesuatu yang selalu berevolusi. Jiwa memiliki tujuh aspek, yaitu mineral, nabati, hewani, pribadi, insani, rahasia dan maharahasia. Setiap aspek memiliki penjelasan masing $\square$ masing dan ditulis dalam bab khusus. Akan tetapi, secara umum, ketujuh aspek jiwa tersebut dapat dicapai secara bertahap dan tasawuf bertujuan agar ketujuh tingkat kesadaran ini bekerja secara seimbang dan harmonis. Taswauf memberikan pendekatan yang sangat holistik, sehingga jiwa terhindar dari bahaya model linear dan hierarkis yang digunakan untuk pembenaran dalam melakukan penindasan terhadap kaum perempuan dan minoritas (Jaenudin, 2012: 161).

Alberto Assagioli merupakan tokoh yang pertama kali menggunakan istilah transpersonal dalam psikoterapi atau dikenal dengan istilah Psikosintesis yang berorientasi menangangani seseorang secara keseluruhan baik, fisik, emosional, mental maupun spiritualnya yang menjadi aspek penyemangat hidup seseorang dalam menjalani kehidupan didunia (Assagioli,1990: 17). Namun didalm Islam juga memiliki Konsep lain yang menunjukan relevansi psikologi transpersonal dalam bidang kesehatan Mental seperti yang di konsepkan Assagioli ialah Shalat, yang merupakan ajaran Islam kedua yang harus dilakukan sehari-hari yang 
merupakan serangkaian gerakan yang dimulai dengan takbir dan dengan diakhiri dengan salam, yang didalamnya terdapat gerakan, berdiri, berlutut dan sujud yang diringi pembacaan doa dengan mengahadp arah yang ditentukan yaitu kiblat. Shalat diperintahkan terus menerus melalui Al-Qur'an. Pertama kali, umat Islam menghadap Yarussalem selama shalat, namun sewaktu Nabi Muhammad Saw. Hidup, terdapat perintah untuk menghadap Ka'bah di kota Mekkah (Aliah, 2008: 126) selain sholat sebagai kewajiban seorang muslim tetapi ada hal lain yang didapatkan ketika melakukannya, yakni manfaat dalam kesehatan mental,Ritual shalat memiliki pengaruh yang sangat luar biasa untuk terapi rasa galau dan gundah. Dengan mengerjakan shalat secara khusyuk akan menghadirkan rasa tenang, tentram dan damai. Sebagaimana firman Allah Swt dalam surat Al-Mu'minun ayat 1-2, yang artinya; sesungguhnya beruntunglah orang-orang yang beriman. (Yaitu) orang-orang yang khusyu dalam sembahyangnya. (Cordova, 2007:342).

Ketika dalam keadaan shock atau ketakutan tubuh dipaksa mengeluarkan reaksi biologis seperti mengeluarkan hormon andrenalin sebagai persiapan untuk menghadapi kondisi tertentu. Hal itu dapat memicu perubahan jiwa dan pikiran karena kondisi susunan syarat terpengaruh dan keadaan kelenjar endokrin yang reaktif (Salim, 2009 dalam Fuad, 2016: 42). Diantara proses psikoterapi dalam shalat adalah membaca atau mendengarkan ayat-ayat Al-Qur'an sebagai obat yang tidak didapatkan di apotik dan rumah sakit. Ahmad Al-Qadzi, ketua pusat informasi Yayasan Ilmu Kedokteran di Amerika mengemukakan hasil percobaan yang menguji keabsahan bacaan al-Qur'an memiliki pengaruh terhadap kesehatan yaitu 97\% Al-Qur'an memiliki pengaruh. Selain manfaat psikoterapi di atas, shalat bermanfaat dalam pembentukan mental seseorang diantaranya mengajari bagaiamana menghargai waktu, disiplin dan sungguh-sungguh dalam melaksanakan aktivitas. Kekuatan spritual juga mampu membangkitkan harapan, memantapkan tujuan, memperkokoh semangat, dan memunculkan kekuatan yang membuat 
seseorang siap menerima ilmu pengetahuan dan hikmah (Fuad, 2016: 43).

Selain shalat juga puasa, dalam ibadah puasa terdapat unsur latihan bagi seseorang untuk bersabar menanggung beban berat kehidupan seperti menahan rasa haus dan lapar, menahan marah serta menahan untuk berbuat yang tidak baik. Dalam sudut sosial, ketika seseorang menahan lapar dan dahaga maka ia akan ikut merasakan penderitaan kaum fakir miskin yang sering kali tidak bisa mengkonsumsi makanan. Rasa empati yang timbul akan mendorong seseorang yang berpuasa mengasihi saudaranya yang bernasib kurang baik secara eknomi. Dia akan memberikan pertolongan dan berbuat baik kepada orang-orang yang membutuhkan sehingga hubungan sosialnya menjadi lebih baik. Kepekaan dan tanggung jawab sosial cenderung mendorong seseorang untuk berbagi sehingga ia merasa sebagai anggota masyarakat yang bermanfaat bagi komunitasnya dan akhirnya ia merasa tentram. Inilah yang disebut oleh Jamaluddin Ancok sebagai hunger project (Fuad:43).

Dari sisi psikis, ibadah puasa berguna untuk mengobati perasaan berdosa dan menghilangkan kegundahan. Rasulullah menyatakan dalam sabdanya: "Barang siapa yang menunaikan puasa ramadhan dilandasi dengna iman dan ikhlas mengharap ridha Allah maka diampuni dosadosanya yang telah lalu. (HR. Al-Bukhari, Muslim, Abu Dawud, Tirmidzi, An-Nasa $\square$ i dan Imam Ahmad). (dalam Fuad: 44). Bahkan beberapa hadits secara spesifik menjelaskan tentang pengampunan dosa tersebut seperti puasa arafah melebur dosa setahun sebelum dan sesudahnya, Asyura melebur dosa setahun sebelumnya, dan sebagainya (Najati, 2003 dalam Fuad: 44).

Ritual ibadah haji seperti thawaf, wujuf, sa'i dan melempar jumrah merupakan kegiatan yang sarat makna. Thawaf dan wukuf di arafah menjadi media meditasi untuk merenungi perbuatan masa lampau yang menjauhkan diri dari Allah swt dan memahami lebih dalam hakikat tujuan hidup. Perjalanan Shafa dan Marwah bermakna perjuangan spiritualitas 
diri untuk bertarung melawan hawa nafsu. Melempar Jumrah „Aqabah mengisyaratkan melempar semua sifat kejahiliahan seperti kemunafikan, kedustaan dan keduniawian. Hal itu adalah gambaran dari kisah perjuangan Nabi Ibrahim yang mengorbankan apa yang dicintai untuk meraih ridha dan kasih sayang-Nya (Suharto, 2002 dalam Fuad: 45).

Menunaikan ibadah haji dapat melatih kesabaran, melatih jiwa untuk berjuang, serta mengontrol syahwat dan hawa nafsu. Ibadah haji menjadi terapi atas kesombongan, arogansi, dan berbangga diri sebab dalam praktek ibadah haji kedudukan semua manusia sama. Permohonan ampunan dan ditambah suasana yang bergemuruh penuh lantunan Ilahi membuat suasana ibadah haji sarat dengan nilai spiritualitas yang dapat mengobarkan rasa semangat yang tinggi untuk meraih ketenangan (Najati, 2003 dalam Fuad: 45). Selain itu, Nabi menghabarkan bahwa ibadah haji dapat melebur dosa melalui sabdanya: "Antara umrah sampai umrah berikutnya dapat melebur dosa-dosa yang ada di antara keduannya, dan haji mabrurtidak ada balasannya kecuali surga (HR. Al Bukhari dan Muslim). (dalam Fuad: 45).

Dzikir dan doa adalah ibadah yang utama dalam Islam bahkan menjadi intinya. Dzikir yang dilakukan akan membuat hati dan jiwa menjadi tenang. Rasulullah mengajari para sahabat untuk senantiasa berdzikir dan berdoa untuk memperkuat hubungannya dengan Allah, dan mendekatkan diri kepada-Nya setiap saaat. Dengan berdoa seorang hamba dapat mengungkapkan isi hatinya dan mencurahkan kegundahannya, mengadu kepada sang pencipta. Hal ini akan memberi efek ketenangan disebabkan keyakinan bahwa Allah akan membantunya keluar dari permasalahan. Allah berfirman: (QS. Al Ghafir: 60) yang artinya "Dan Tuhan-mu Berfirman, "Berdoalah kepada-Ku, niscaya akan Aku Perkenankan bagimu. Sesungguhnya orang - orang yang sombong tidak mau menyembah-Ku akan masuk neraka Jahannam dalam keadaan hina dina." (QS. Al Ghafir: 60, Cordova, 2007:474). 
Dari uraian diatas dapat disimpulkan bahwa metode penguatan dimensi spiritual dilakukan melalui tiga tahapan yaitu menanamkan iman dan tauhid, mengarahkan tujuan hidup dan melaksankan ibadahibadah yang disyariatkan dalam agama. Jika tahapan-tahapan ini mampu dilaksanakan dengan baik maka kepribadian yang mantap dan kepribadian yang baik akan terbentuk dan pada akhirnya mengantarkan seseorang kepada kebahagiaan dan kesehatan mental bahkan mampu mengembangkan potensi diri secara optimal.

\section{Simpulan}

Ada banyak kosepsi mengenai defenisi manusia dimulai dari perspektif filsafat, ekonomi, sosial, pendidikan dan juga konsep dari dunia Islam, tentu saja hal itu sangatlah relevan dengan kajian dengan Psikologi. Hanya saja pendekatan Psikologi terkadang dengan menggunakan pendekatan eksperimental dalam upaya mengungkapkan defenisinya, malah hal itu berusaha mengkokohkan defenisi-defenini menganai manusia itu sendiri yang sebelumnya diungkapkan dalam dispilin ilmuilmu yang lain namun.

Konsep manusia dalam pandangan Psikologi Transpersonal; (1) Naluri adalah tenaga atau kuasa awal yang mendorong seorang individuuntuk bertindak dengan cara tertentu. Ia merupakan tingkah laku yang diwarisi sejak lahir dan tidak diperoleh dari pengalaman ataupun pelajaran; (2) Keperluan adalah keinginan memenuhi kekurangan seorang individu dariaspek fisiologi dan psikologi; (3) Desakanadalah tindakan atau perubahan tingkah laku akibat satu-satu keperluan fisiologi yang tidak dipenuhi. Ia merupakan kecendrungan untuk mengekalkan keseimbangan suatu keadaan fisiologi seperti lapar dan dahaga; (4) Motivasiadalah perangsang yang membangkitkan dan mengekalkan minatseorang individu ke arah mencapai suatu sikap tertentu, termasuk mengubah sikap, minat dan tingkah lakunya. Lalu transpersonal dalam konsep Islam ialah 
optimalisasi potensi manusia terhadap nilai-nilai ke Tuhanannya, yang dilakukan dikalangan sufi dalam upaya menemukan jalan menuju kepada Tuhan, melalui stasiun (maqom) dimulai dari taubat, zuhud, rida, tawadhu, mahabbah dan ma'rifah yang manifestasi dari hal tersebut optimalisasi nilainilai Ketuhanan dalam diri manusia. Aspek psikologi transpersonal yang sangat berkeorelasi dalam Islam khususnya dalam bidang penyembuhan penyakit mental ialah melalui sholat, puasa, zikir, doa,dan haji, karena para pelaku yang menjalankan ibadah ini akan mendapatkan ketenangan batin yang bisa menjadi solusi bagi mereka yang depresi, shock atau ketakutan.

Setiap konsep dan teori yang diajukan oleh para tokoh psikologi ini dilatarbelakangi oleh masa lalu dan pengalaman yang telah mereka lalui.Pada setiap teori memiliki kelebihan dan kekurangan masing-masing. Meskipun penulis berupaya mengekplorasi sejauh mana konsep psikologi transpersonal dalam Islam ini, tentu saja penulis mendapat kendala dalam upaya pengkajian tersebut dikarenakan keterbatasan, tetapi masih kekurangan tersebut bisa menjadi rekomendasi kedepan bagaimna upaya penggalian kosep psikologi terutama psikologi transpersonal dalam Islam itu menuju lebih detail lagi bukan hanya konsep tasawuf, sufi, shalat, puasa, zikir, doa dan haji semata, tetapi ada hal lain yang bisa dikaji. Tidak semua konsep Islam bisa sejalan dengan teori barat dan sebagiannya justru bertentangan.

\section{Daftar Pustaka}

Abidin, Zaenal."Perbandingan tujuan pendidikan dalam membentuk manusia Ideal menurut Paulo Friere dan Muhammad Iqbal". Junal Suhuf, Vol 3 Tahun 2018

Ady, A. N. 2012. "Psikologi Transpersonal Konsep Dan Implementasinya Terhadap Pendidikan Dan Globalisasi”. Al 'Ulum Vol. 54 No. 4 Tahun 2012.

Ali, Rahmat. "Konsep manusia dalam Persepektif Filsafat Pendidikan Islam Ibn Sina dan Al-Ghazali”. Jurnal Kuttab, Volume 1 No 1 Maret 2017 
Assagioli.1990. Psychosynthesis. Wellingborough: Crucible

Capra Fritjof. 1997. Titik Balik Peradaban. Penerjemah. M. Toyyibi. Yogyakarta: Yayasan Bentang Budaya.

Cordova. 2007. Al-Qur'an dan Terjemah. Bandung: Sygma Exagrafika.

Dharsana, I. K, Arnikawati \& Suranata. "Penerapan Konseling Eksistensial Humanistik Dengan Teknik Bermain Peran Untuk Meningkatkan Kecerdasan Emosional Siswa Kelas VIII A2 SMP Negeri 4 Singaraja".

Undiksa Jurusan Bimbingan Konseling, Vol 2 No 1 tahun 2014 Drijarkara. 1978. Percikan Filsafat. Semarang: Kanisius

Feist, J., \& Feist, G. J. 2008. Theories of Personality. Yogyakarta: Pustaka Pelajar.

Fuad, Ikhwan. 2016. "Menjaga Kesehatan Mental persepektif al-Qu'an dan Hadist". Jurnal An-Nafs. Vol 1 No 1 Tahun 2016.

Hall, C.S \&Lindzey, G. 1995. Psikologi Kepribadian 2 Teori-teori Holistik (Organismik-Fenomenologis). Yogyakarta: Kanisius.

Hambali, A \& Jaenudin, U. 2013. Psikologi Kepribadian Lanjutan (Studi atas Teori dan Tokoh Psikologi Kepribadian). Bandung: CV Pustaka Setia. Jaenudin, U. 2012. Psikologi Transpersonal. Bandung: CV Pustaka Setia. Margono, S. 2007. Metodologi Penelitian Pendidikan. Jakarta: Rineka Cipta. Purwakanian, Hasan Aliah B. 2008, Pengantar Psikologi Kesehatan Islami. Jakarta: PT. Raja Grafindo.

Seligman, M. E. 2005. Authentic Happiness: Menciptakan Kebahagiaan dengan Psikologi Positif. Bandung: Mizan.

Tamir, M., Schwartz, S. H., Oishi, S., \& Kim, M. Y. "The Secret of Happiness: Feeling Good or Feeling Right?". Journal of Experimental Psychology: General. 2017.

Whitmore, D. 1991. Psychosynthesis Counselling In Action. London: Sage Wnuk, M., \& Marcinkowski. JT. "Do Existential Variables Mediate Between Religious-Spiritual Facets of Functionality and Psychological Wellbeing". Journal Religion Health. 2014.

Zuhairini. 2009. Filsafat Pendidikan Islam. Jakarta: Bina Aksara 